\title{
Local and Duration Magnitude Determination for the Italian Earthquake Catalog, 1981-2002
}

\author{
by B. Castello, M. Olivieri, and G. Selvaggi
}

\begin{abstract}
In the present work, we update magnitude estimates of the instrumental catalogue of 99,780 Italian earthquakes that occurred during 1981-2002. The catalog contains a large data set of $P$ - and $S$-arrival times and accurate earthquake locations. We derive duration magnitude estimates from linear regression between local magnitude calculated from Mediterranean Very Broadband Seismographic Network (MedNet) and the corresponding seismic-signal durations at the national network Rete Sismica Nazionale Centralizzata (RSNC). We introduce a station correction factor $S c_{j}$ because of most of the stations located in southern Italy show large residuals that appear to be of regional importance. The relation obtained:
\end{abstract}

$$
M_{d_{i j}}=2.49 \cdot \log \left(T_{i j}\right)-2.31+S c_{j} .
$$

$\log M_{0}-M_{\mathrm{L}}$ and $M_{\mathrm{W}}-M_{\mathrm{L}}$ relations are also computed in the range of 3.5-5.8 from regional centroid moment tensor estimation of medium-strong Italian earthquakes, by linear regressions. We obtained best least-square fits for:

$$
\begin{aligned}
& \log M_{0}=1.18( \pm 0.06) \cdot M_{\mathrm{L}}+10.92 \\
& M_{\mathrm{w}}=0.79( \pm 0.4) \cdot M_{\mathrm{L}}+1.20
\end{aligned}
$$

Introduction

A catalog of relocated Italian earthquakes over the past 22 years (1981-2002) is now available at Istituto Nazionale di Geofisica e Vulcanologia (INGV) web site (Italian Seismic Catalogue, CSI 1.0, Castello et al., 2005). The catalog includes locations and $P$ - and $S$-wave arrival times at the national and several regional seismic networks operating on Italian territory. The location procedure and velocity model are described in Chiarabba et al. (2005). They relocated the earthquakes with a homogeneous procedure, adapting and optimizing location parameters.

Chiarabba et al. (2005) compiled a catalog of $P$ - and $S$ wave arrival times from bulletins for the period 1997-2002, including data from the INGV national network Rete Sismica Nazionale Centralizzata (RSNC) and several regional networks (Fig. 1). All the arrival times were associated, based on those by individual networks and propagation times for $P$ waves, and carefully reanalyzed to find possible errors or inconsistencies. This catalog was added to the pre-existing 1981-1996 associated arrival times (ICWG, 2001). The final dataset consists of about 1,407,000 $P$-wave arrivals and $609,013 S$-wave arrivals for the whole period. Locations have been obtained with an optimized 1D velocity model, cautiously selecting the location-weighting parameters, both using sharp weighting parameters to enhance the information at close stations or using smooth weighting parameters to locate events recorded only at a few and distant seismic stations. The work of Chiarabba et al. (2005) does not explore magnitude determination. That is the goal of this article.

In this work, we propose an updated version of log of duration versus local magnitude scale by regression analysis for the catalog. The regression coefficients have been calibrated from 1996-2000 revised local magnitude from broadband stations recordings and the corresponding duration estimates from national network (RSNC) short-period stations data. Since 1996, Mediterranean Very Broadband Seismographic Network (MedNet) data have been used to compute automatic simulated Wood-Anderson magnitude and regional centroid moment tensor estimation (Pondrelli et al., 2002) for medium-strong earthquakes of the Mediterranean area. More than 5000 revised local magnitudes for Italian earthquakes from MedNet seismic network are available for the period 1996-2000. The magnitude range covered by the revised $M_{\mathrm{L}}$ estimates varies from 0.8 to 5.6.

The regression coefficients and station corrections have been applied to the entire catalog 1981-2002 of relocated earthquakes. The threshold of applicability is limited up to $4.9 M_{\mathrm{L}}$, because signal durations for stronger earthquakes are usually not estimated. For $M_{\mathrm{L}}>4.9$, local magnitude is taken from the available catalogs. The completeness of $M_{\mathrm{L}}>4.5$ is checked on the basis of International Bulletins 


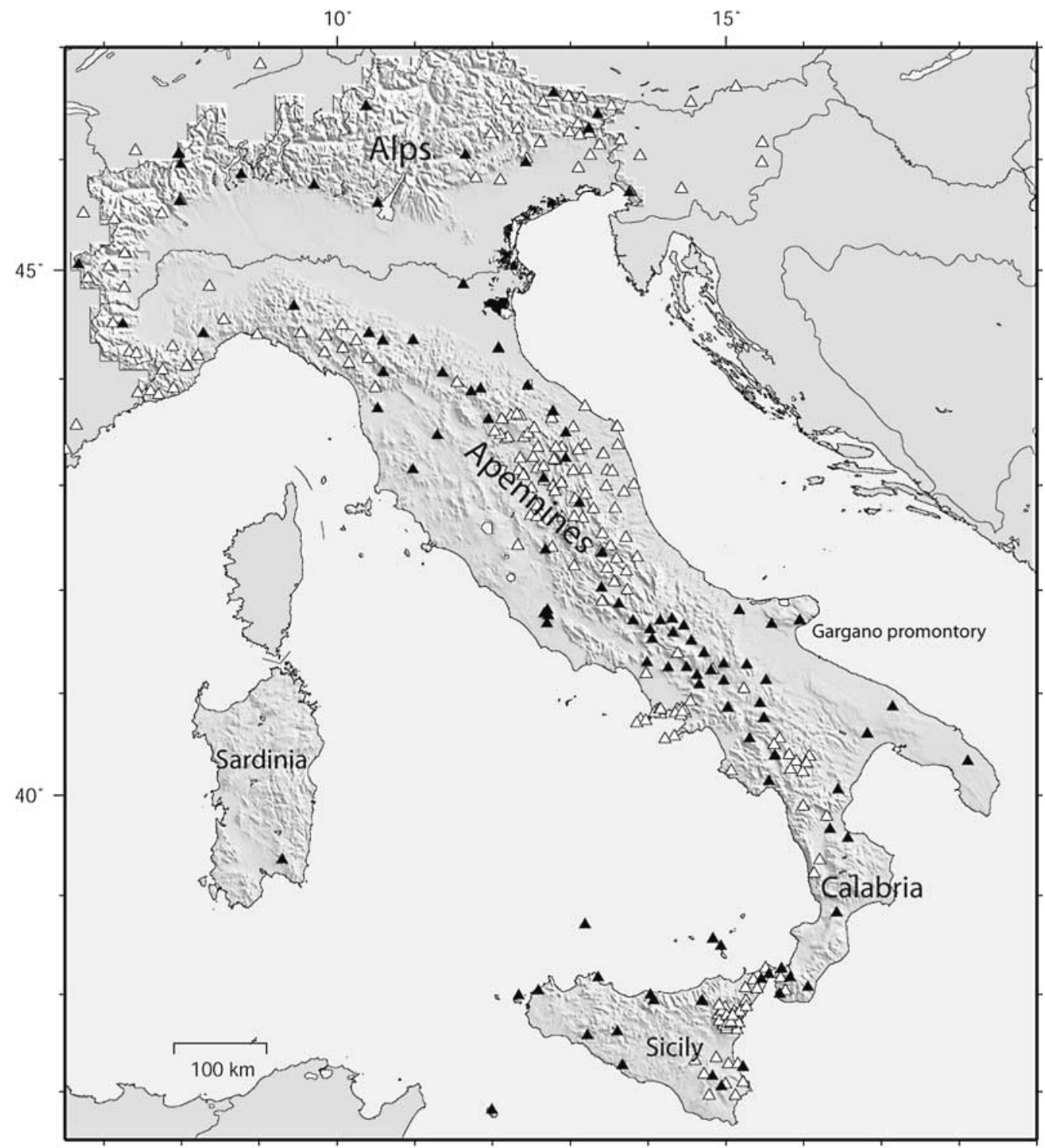

Figure 1. Distribution of permanent seismic stations managed by different Italian and European institutions (filled triangles = RSNC stations managed by INGV; open triangles $=$ other institutions).

by the National Earthquake Information Center (NEIC) and the International Seismological Centre (ISC).

Finally, we performed regression analysis to obtain $M_{\mathrm{L}}$ versus $\log M_{0}$ and $M_{\mathrm{L}}$ versus $M_{\mathrm{w}}$ calibrations using the $M_{\mathrm{L}}$ data set collected and the 1997-2000 Italian earthquakes database from regional centroid moment tensor estimation for medium-strong earthquakes of the Mediterranean area (Pondrelli et al., 2002).

Duration Magnitude Scale for Italian Earthquakes scale is

A general formulation for the duration magnitude

$$
M_{\mathrm{d}}=a \cdot \log (\tau)+b \cdot \Delta+c
$$

with $\tau=$ duration observations and $\Delta=$ epicentral distance in kilometers. Several authors (Real and Teng, 1973; Bakun, 1984; Michaelson, 1990; Eaton, 1992; Mouayn et al., 2004) proposed different duration magnitude models, including hypocentral distance factor, site correction, and instrument correction.

The magnitude duration scale used at INGV computed by Console et al. (1988) was not calibrated on $M_{\mathrm{L}}$ WoodAnderson magnitude but derived from the Lee et al. (1972) formula. The scale accounts for epicentral distance and is

$$
M_{\mathrm{d}}=a \cdot \log (\tau+b \cdot \Delta)+c,
$$

with $a=2.0, b=0.082$, and $c=-0.87$. Malagnini et al. (2000) and Gasperini (2002) noticed that $M_{\mathrm{D}}$ provided by 


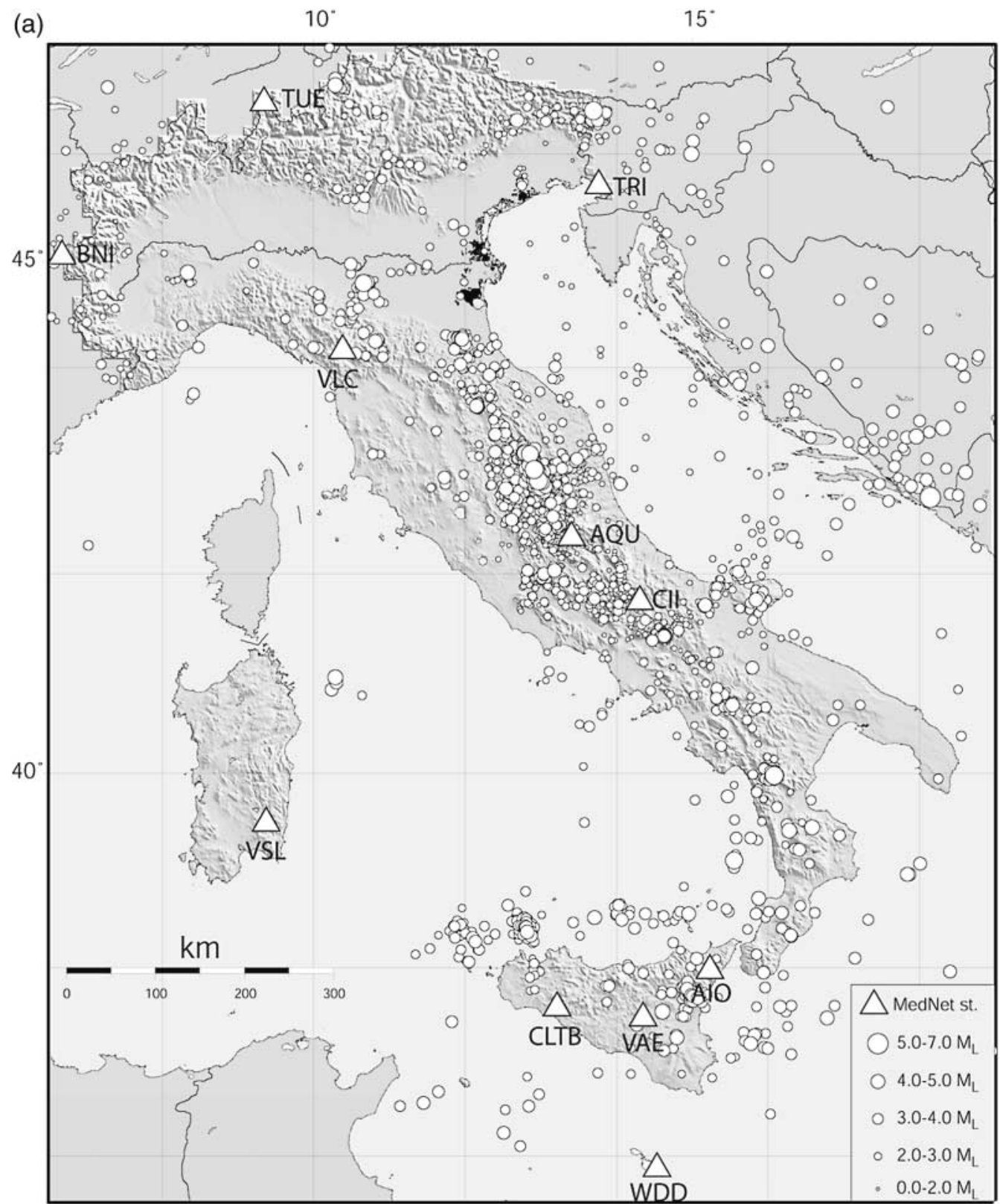

Figure 2. (a) 1996-2000 Italian earthquakes with $M_{\mathrm{L}}$ computed by MedNet Data Centre. Open triangles are for MedNet network seismic stations.

(continued)

INGV underestimates the magnitude for events larger than 3.4. Moreover, in Gasperini (2002) a clear overestimation of magnitude by using Console et al. (1988) formula for smaller earthquakes is observed.

\section{Data}

The $M_{\mathrm{L}}-$ MedNet Data Set

Since 1996 an automatic system (MUSCLES) interacts with stations of MedNet providing reliable and real-time local magnitudes for the strongest earthquakes $\left(M_{\mathrm{L}}>3.8\right)$ in the Mediterranean region (Mazza et al., 1998). The auto- matic procedure, routinely used at INGV, operates the deconvolution of the velocity-response spectrum of the VBB seismometer to obtain the ground displacement and subsequently the convolution of the latter with the response of the Wood-Anderson seismometer. The maximum amplitude is automatically detected for each time series as well as the arithmetic average of the amplitude of the two horizontal components of each station to determine the local magnitude according to the Richter definition. Distance corrections correspond to Richter attenuation function parameters computed for California, because they satisfy the attenuation function characteristics of Italy (Gasperini, 2002). The final 


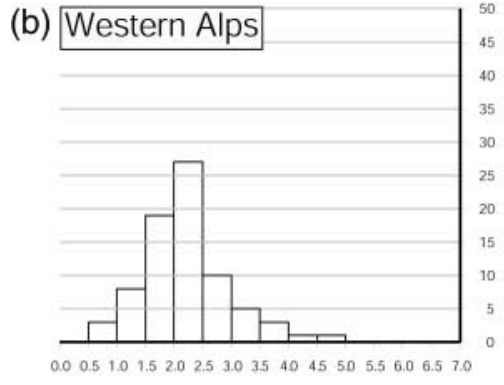

$\mathrm{M}_{\mathrm{L}}$

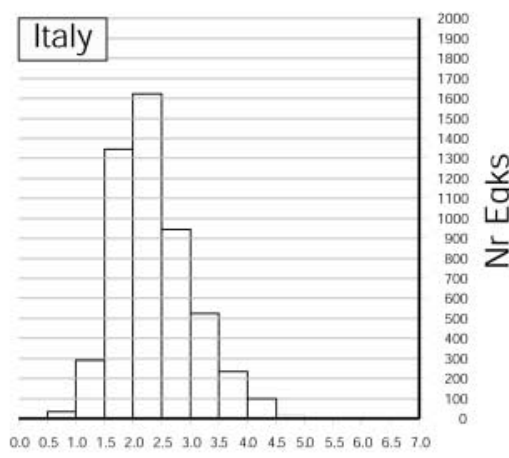

$\mathrm{M}_{\mathrm{L}}$

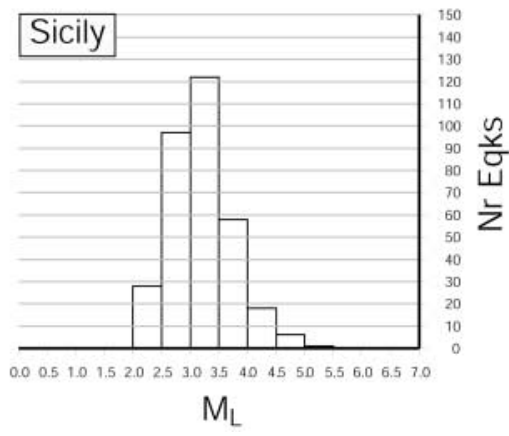

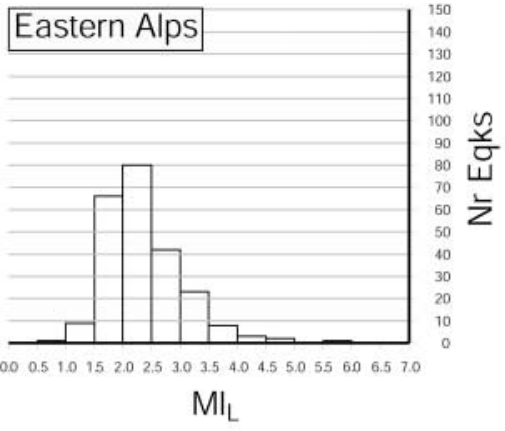

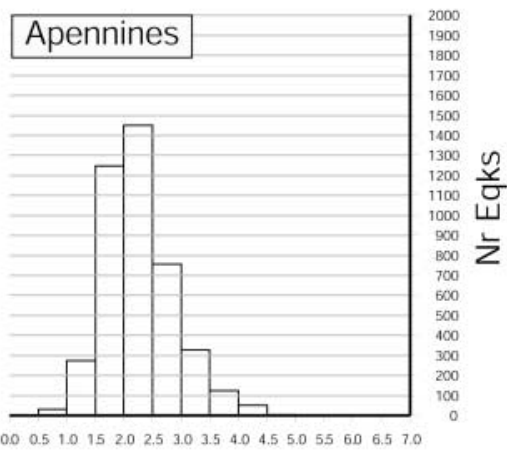

$\mathrm{M}_{\mathrm{L}}$

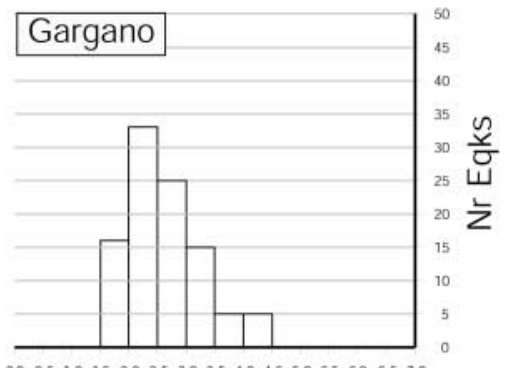

$\mathrm{M}_{\mathrm{L}}$

Figure 2. (continued) (b) Frequency distribution of 1996-2000 Italian earthquakes with $M_{\mathrm{L}}$ computed by MedNet Data Center: entire data set (left middle); regional subsets (all others). For geographical references see Figure 1.

$M_{\mathrm{L}}$ is derived from the average values obtained at different stations and the standard deviation is also computed.

MedNet data are available since 1990 with a few stations, but the network expanded during the past fourteen years and at present counts 21 stations. This created the capability to produce a catalog of 5068 revised local magnitude earthquakes from 1996 up to 2000 estimated with accuracy. The magnitudes were computed using all available recordings for each event, discarding data with bad signal-to-noise ratios. Distance factors are improved by using the more accurate hypocentral location of the INGV Bulletin. The 1996$2000 M_{\mathrm{L}}$-MedNet data set covers the Italian region well, with a concentration in the Central Apennines, where the $M_{\mathrm{w}} 6.01997$ Colfiorito sequence occurred (Fig. 2a). $M_{\mathrm{L}}$ ranges from 0.8 to 5.6; the most representative class of magnitude corresponds to $2.0<M_{\mathrm{L}}<3.0$ (Fig. 2b).

\section{Duration Estimates}

Duration estimates of Italian earthquakes are available from bulletins of each Italian seismological observatory that manages national or regional permanent networks. The estimate of event duration is visually defined by the analysts from $P$-onset time until the point when the signal envelope decays down to the pre-event noise level. Nevertheless, definition of event duration is not homogeneous at each observatory. Because the visual determination produces some bias in the earthquakes catalogs, we have preferred to select only durations coming from RSNC stations to avoid summation of different catalog biases, which means seismic events recorded exclusively by regional permanent networks are not included in the 1996-2000 $M_{\mathrm{L}}$ durations data set. The data set consists of 4929 earthquakes with 21,995 RSNC duration estimates: $21 \%$ of earthquakes have five or more duration 

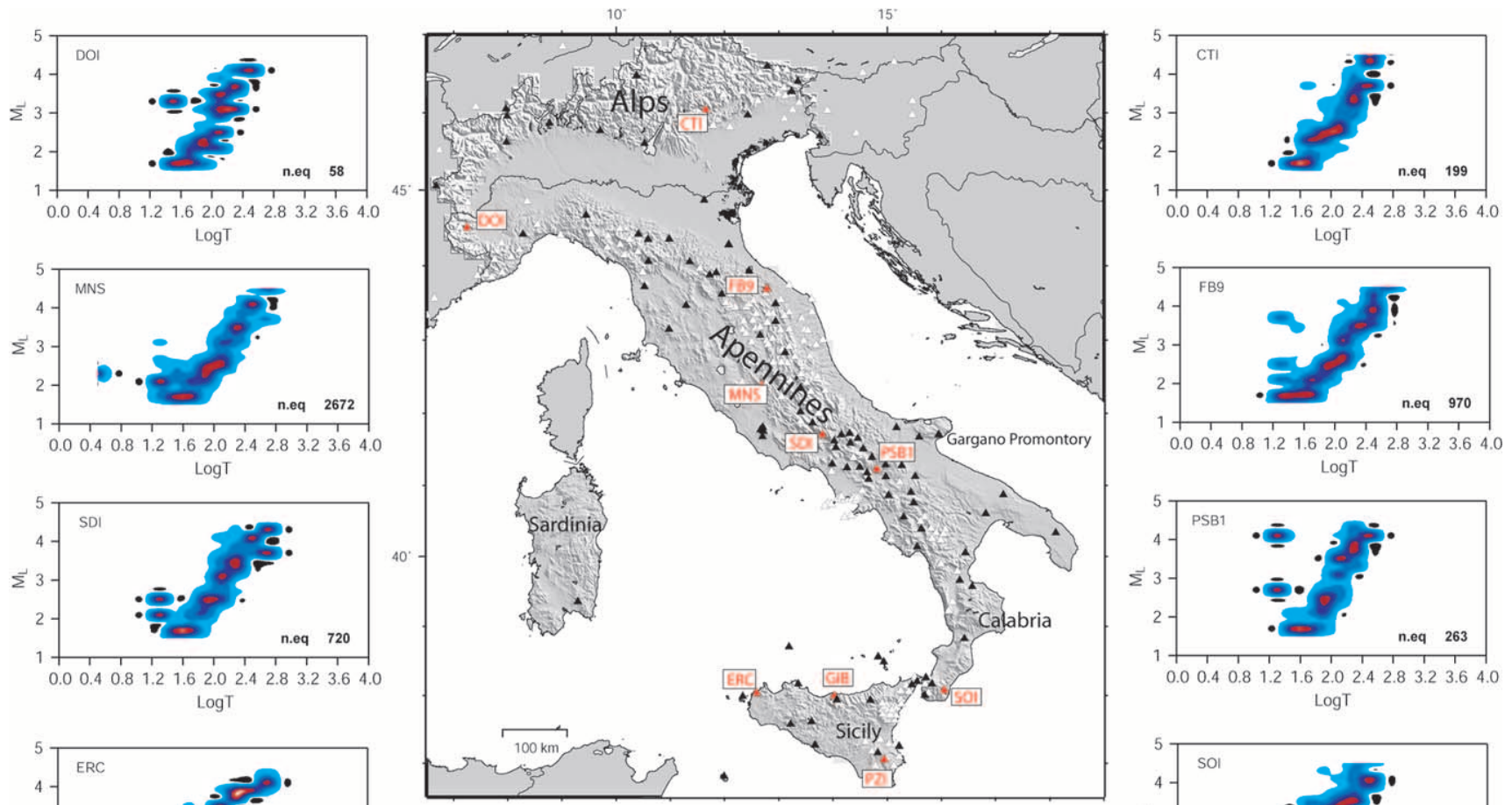

$\log \mathrm{T}$
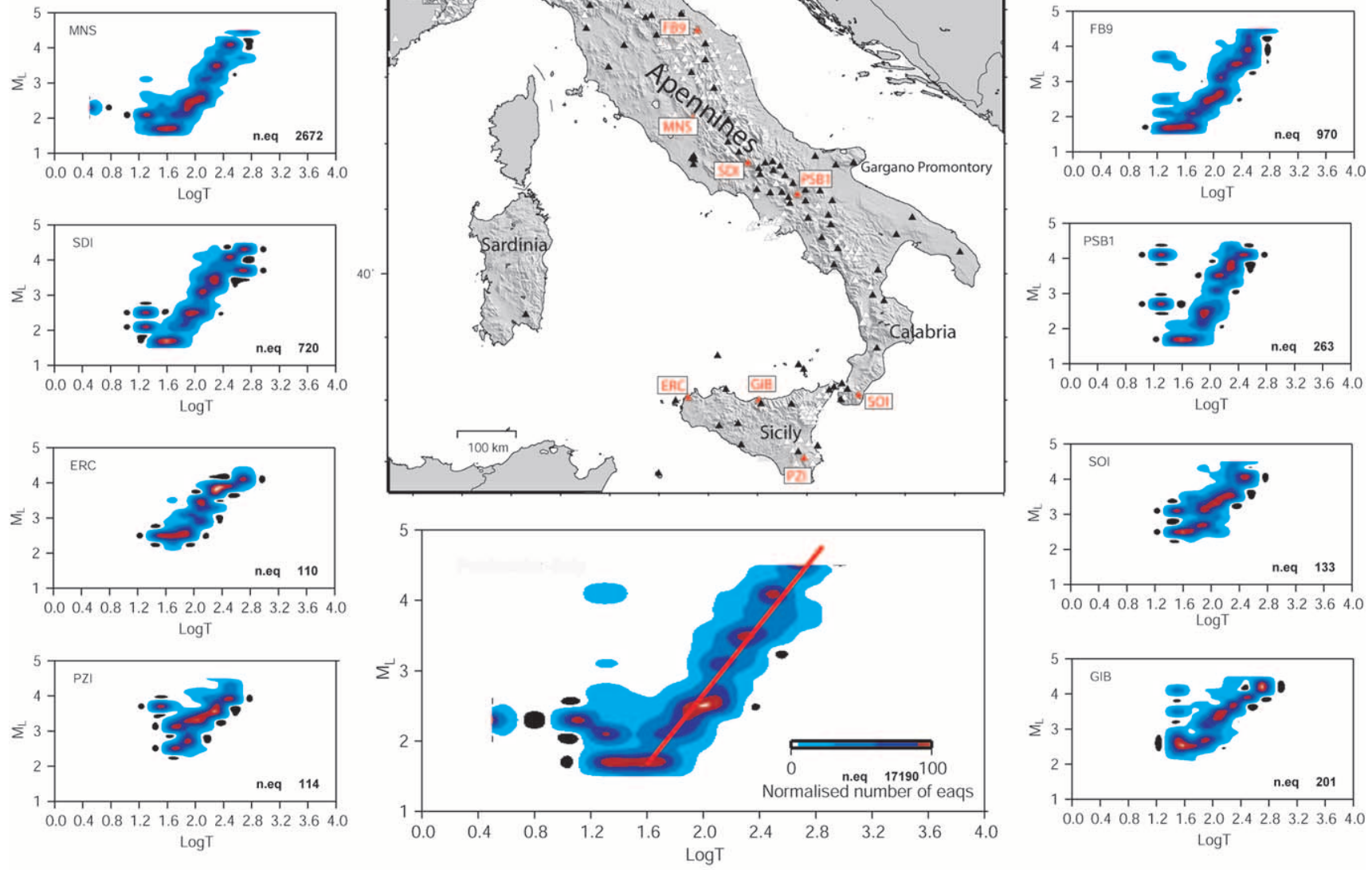

Figure 3. $\quad M_{\mathrm{L}}$ versus logarithm of duration $(T)$ observations at seismic stations located along the Italian Peninsula and Sicily. Duration observations are plotted by frequency per magnitude normalized to 100 . Plots show a different trend at Sicilian and Southern Calabria stations (ERC, PZI, SOI, GBM). (bottom center) The $M_{\mathrm{L}}$ versus logarithm of duration plot for the Peninsular Italy stations recordings only. The red line corresponds to equation (3).

estimates. The data set is mainly contained within the first $100 \mathrm{~km}$ of station distance from the epicenter. This implies that the estimate of a regression coefficient associated with distance will not be well constrained. Besides, shallow crustal earthquakes are most of the data set.

We then analyzed the data set station by station. Figure 3 shows some representative samples of $M_{\mathrm{L}}$ versus $\log$ of duration distribution for Italian stations. The data, though largely scattered, show a similar trend for stations located in the Alps and in the Apennines. Stations in Sicily and in Southern Calabria clearly have a different trend, suggesting that attenuation properties of the crust may differ considerably across Italy (Scognamiglio et al., 2005, and references therein). Accordingly, we calculated the coefficients of the model (1) by using linear least-squares multiple regression and dividing the data set in two subsets taking into account the observations from Figure 3. A least-squares regression method implies that the independent variable is not affected by error, and the dependent variable has errors normally distributed. Duration estimates and $M_{\mathrm{L}}$ are both affected by error and variance is difficult to estimate. In any case the error in the $\log$ of duration derived from duration estimate is approximately four times less in percentage than the $M_{\mathrm{L}}$ estimate error. Thus we avoid the use of orthogonal regression methods (Carrol and Ruppert, 1994). Furthermore, for the same reason, the choice of the dependent variable as Log of duration is justified and we did not investigate a maximumlikelihood parameter estimation (Stroymer et al., 2004). 
Table 1

Regression Results and Analysis of Variance

\begin{tabular}{lcccccc}
\hline & & & \multicolumn{2}{c}{ Network Subset: Weighted and Limited Data Set } \\
\cline { 2 - 6 } & $\mathrm{a}$ & $\mathrm{c}$ & Standard Error & $R^{2}$ & \multirow{2}{*}{$F$ Test } & \multicolumn{2}{c}{ No. of Degrees of Freedom } \\
\hline Peninsular Italy and Sardinia & 2.485253 & -2.31379 & 0.347566 & 0.779386 & 5468.774 \\
Sicily and Messina Strait & 1.313947 & 0.614009 & 0.392016 & 0.596361 & 2895.829 \\
\hline
\end{tabular}

Table 2

Station Corrections for 82 of the 99 RSNC Stations of 1996-2000 $M_{\mathrm{L}}$ MedNet Durations Data Set

\begin{tabular}{|c|c|c|c|c|c|c|c|}
\hline Station Code & $d S t a_{j}$ & $\delta_{j}$ & $N$ & Station Code & $d S t a_{j}$ & $\delta_{j}$ & $N$ \\
\hline $\mathrm{AQU}$ & -0.0248 & 0.0116 & 1042 & MDI & 0.1877 & 0.0563 & 38 \\
\hline $\mathrm{ARV}$ & 0.0765 & 0.0105 & 1366 & MEU & 0.7768 & 0.0528 & 72 \\
\hline ASS & 0.0114 & 0.0067 & 2796 & MGR & 0.1904 & 0.0466 & 108 \\
\hline ATN & 0.5483 & 0.0487 & 58 & MNO & 0.5919 & 0.0359 & 162 \\
\hline AU9 & 0.6172 & 0.0384 & 122 & MO9 & 0.5319 & 0.0337 & 142 \\
\hline BAI2 & -0.0734 & 0.0411 & 67 & MPG & 0.2278 & 0.063 & 23 \\
\hline BDI & 0.2155 & 0.0398 & 118 & MSI & 0.7669 & 0.0933 & 29 \\
\hline BR9 & 0.0528 & 0.0399 & 98 & MU9 & 0.1108 & 0.0259 & 260 \\
\hline BRT & 0.4657 & 0.0442 & 80 & NRCA & -0.1171 & 0.0107 & 995 \\
\hline BS9 & 0.3819 & 0.1381 & 10 & ORI & 0.3229 & 0.0467 & 101 \\
\hline CA9 & 0.1524 & 0.0416 & 80 & PGD & 0.1266 & 0.0406 & 90 \\
\hline CI9 & 0.1634 & 0.0353 & 179 & PII & 0.2615 & 0.0501 & 86 \\
\hline CLTB & 0.4303 & 0.0524 & 32 & PLI2 & 0.1356 & 0.05 & 77 \\
\hline CRE & 0.0903 & 0.0233 & 363 & PQ9 & 0.0355 & 0.0152 & 523 \\
\hline CRV1 & -0.055 & 0.0368 & 167 & PSB1 & -0.0755 & 0.0259 & 230 \\
\hline CS9 & 0.6198 & 0.0429 & 97 & PTCC & -0.0992 & 0.0306 & 168 \\
\hline CSNT & 0.26 & 0.038 & 207 & PTS & 0.5467 & 0.0546 & 17 \\
\hline CTI & -0.0351 & 0.0275 & 199 & PZI & 0.6081 & 0.039 & 114 \\
\hline DSB1 & 0.0981 & 0.0578 & 40 & RDP & 0.1476 & 0.0346 & 89 \\
\hline DUI & -0.1101 & 0.0258 & 160 & RFI & 0.0726 & 0.0306 & 170 \\
\hline EB9 & 0.0968 & 0.0418 & 126 & RGNG & 0.217 & 0.0653 & 61 \\
\hline ERC & 0.4187 & 0.0304 & 106 & RMI2 & 0.0609 & 0.0521 & 52 \\
\hline FAI & 0.5951 & 0.0792 & 26 & RMP & 0.1587 & 0.0478 & 58 \\
\hline FAVR & 0.5744 & 0.079 & 36 & RNI2 & -0.1757 & 0.0502 & 58 \\
\hline FB9 & 0.0351 & 0.0104 & 936 & RSM & 0.1678 & 0.03 & 125 \\
\hline FG2 & 0.178 & 0.0333 & 122 & RV12 & -0.1476 & 0.0282 & 117 \\
\hline FG3 & 0.2039 & 0.039 & 94 & SAI & 0.6472 & 0.0704 & 62 \\
\hline FG4 & 0.2254 & 0.0571 & 57 & SAL & 0.193 & 0.0539 & 90 \\
\hline FG5 & 0.0956 & 0.032 & 141 & SC9 & 0.6382 & 0.0656 & 46 \\
\hline FVI & -0.0355 & 0.0298 & 206 & SDI & -0.0406 & 0.0139 & 665 \\
\hline GE9 & 0.0797 & 0.0328 & 146 & SFI & 0.0651 & 0.0161 & 416 \\
\hline GIB & 0.5121 & 0.0272 & 195 & SGO & 0.1968 & 0.0251 & 254 \\
\hline GMB & 0.7706 & 0.0756 & 9 & SL9 & 0.3176 & 0.0354 & 150 \\
\hline GRFL & 0.3784 & 0.117 & 27 & SMB1 & -0.1729 & 0.0205 & 273 \\
\hline GRI & 0.5934 & 0.0473 & 88 & SNTG & -0.0234 & 0.0155 & 777 \\
\hline GU9 & 0.116 & 0.0457 & 118 & SOI & 0.5564 & 0.0362 & 131 \\
\hline LCI & 0.8096 & 0.109 & 21 & TDS & 0.4563 & 0.0571 & 85 \\
\hline LT9 & 0.3694 & 0.045 & 88 & TRI & 0.1336 & 0.0451 & 93 \\
\hline LVI & 0.5044 & 0.0323 & 77 & USI & 0.3616 & 0.0404 & 60 \\
\hline MAB1 & 0.0469 & 0.0421 & 71 & VVI & 0.1738 & 0.0735 & 35 \\
\hline MCT & 0.5824 & 0.0927 & 9 & ZC9 & 0.0946 & 0.0441 & 166 \\
\hline
\end{tabular}

\section{Data Analysis}

\section{Regression Analysis}

Data have been differently selected, either limiting the duration observations to $\log (T)=1.7(T \sim 50 \mathrm{sec})$ as minimum or weighting by the frequency of durations per mag- nitude, to prevent possible bias caused by the nonuniform data distribution. One general conclusion from these tests is the poor contribution of the distance factor $b$ since most of the durations estimates come from stations with epicentral distance shorter than $100 \mathrm{~km}$ and the $b$ factor is not very sensitive at this short distance range. 
Results show (Table 1) a good fit for Peninsular Italy subset $\left(R^{2}=0.78\right)$, whereas the coefficient parameters are not well constrained for Sicilian subset $\left(R^{2}=0.60\right)$.

Model variance also did not improve for different Sicilian subnets, suggesting that a linear relationship as (1) is not valid for the data distribution. We infer that the presence of Mt. Etna volcano, as well as large crustal heterogeneities across this region, are responsible for this behavior. Therefore, we choose to adopt a conservative strategy for calculating station corrections, as described in the next section, to avoid the arbitrary further selection of the data set. In summary, the formula calculated for the whole data set is the following:

$$
M_{\mathrm{d}_{i j}}=2.49( \pm 0.03) \cdot \log \left(T_{i j}\right)-2.31( \pm 0.08),
$$

where $i$ and $j$ represent the $i$ th event recorded at the $j$ th station, while $a$ and $c$ coefficients of model (1) correspond to Peninsular Italy regression analysis parameters.

\section{Station Corrections}

Station corrections were computed using equation (3). Given the arguments for representing the source by a scalar, the station corrections represent additional propagation path and seismograph effects (Bakun, 1984; Michalson 1990). They are introduced to reduce the particular effect of the site of each station. $S c_{j}$ is the station correction at $j$ th station of the network and is defined:

$$
S c_{j}=\frac{\sum_{i}\left(M_{L}-M_{\mathrm{d}_{i j}}\right)}{N} .
$$

$\sigma_{j}$ is the standard deviation of the mean:

$$
\sigma_{j}=\sigma / \sqrt{N}
$$

and $N$ is the number of events recorded at each station. Stations with numbers of recorded events $N<9$ are excluded from station correction estimates and station corrections with $\left|\sigma_{j}\right|>S c_{j}$ are not considered.

The final formula adopted is:

$$
\begin{aligned}
M_{\mathrm{d}_{i j}}^{*}=2.49( \pm 0.03) \cdot \log \left(T_{i j}\right) & \\
& -2.31( \pm 0.08)+S c_{j} .
\end{aligned}
$$

Station corrections range from -0.18 and 0.81 magnitude units with a maximum standard deviation of 0.14 units from the mean (Table 2); the highest values come from stations in Sicily and Southern Calabria (Fig. 4). The applications of the station corrections reduces the total $\mathrm{rms}$ from 0.44 to 0.40 for $M_{\mathrm{d}_{i j}}^{*}$ estimates from equation (6). $M_{\mathrm{d}}$ of the event will be the arithmetic average of $M_{\mathrm{d}_{i j}}^{*}$

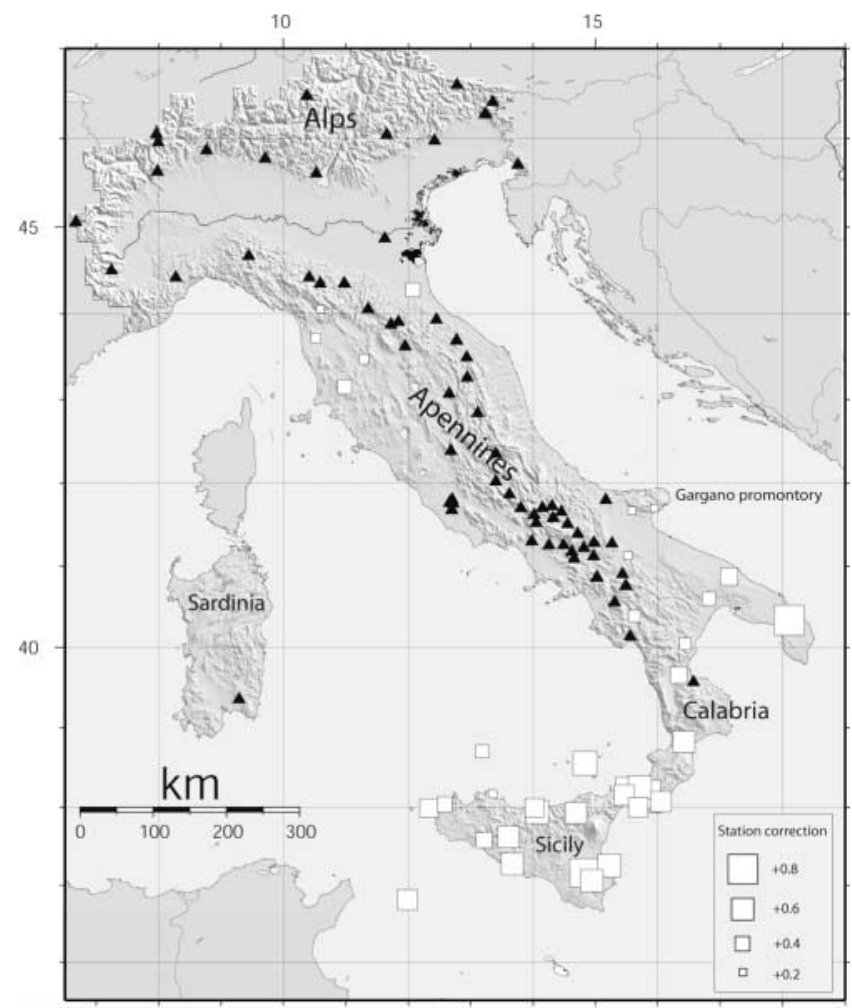

Figure 4. Station correction distribution for $S c_{j}>$ +0.2 : negative values in this range were not found. Filled triangles are for stations without significant correction.

\section{Residuals Analysis and Tests}

We define the station residual as the difference between $M_{\mathrm{d}_{i j}}^{*}$ and the mean $M_{\mathrm{d}}$ for an individual station. We plot all the station residuals versus epicentral distances $\Delta$ and $\log$ (T) (Fig. 5a,b). This allows us to check if station residuals are correlated with $\log (T)$ or epicentral distances $\Delta$. The misfit is small and normally distributed within twice the standard deviation $(2 \sigma=0.28)$, and are clearly uncorrelated with respect to both quantities.

We then compared $M_{\mathrm{d}}$ with $M_{\mathrm{L}}$ MedNet in the same interval (1996-2000). The best fit would be represented by a 1:1 trend. Figure $6 a$ and $b$ shows the expected trend, with a slight improvement when using stations correction (Fig. 6b). This result was expected as the regression coefficients have been obtained from the same data set. $1727 M_{\mathrm{L}}$ MedNet of Italian earthquakes that occurred during 2001-2002 and computed in this study were used as an independent data set. When an independent data set is used for the same test, the fit is not as good, but the use of station corrections strongly improves the $M_{\mathrm{L}}$ estimate, at least in the interval covered by the data (Fig. 7a,b).

Finally, Figure 8 shows the same test using the presentday formula used at INGV (Console et al., 1988), where the already stated overestimation at low magnitude is clearly visible. 


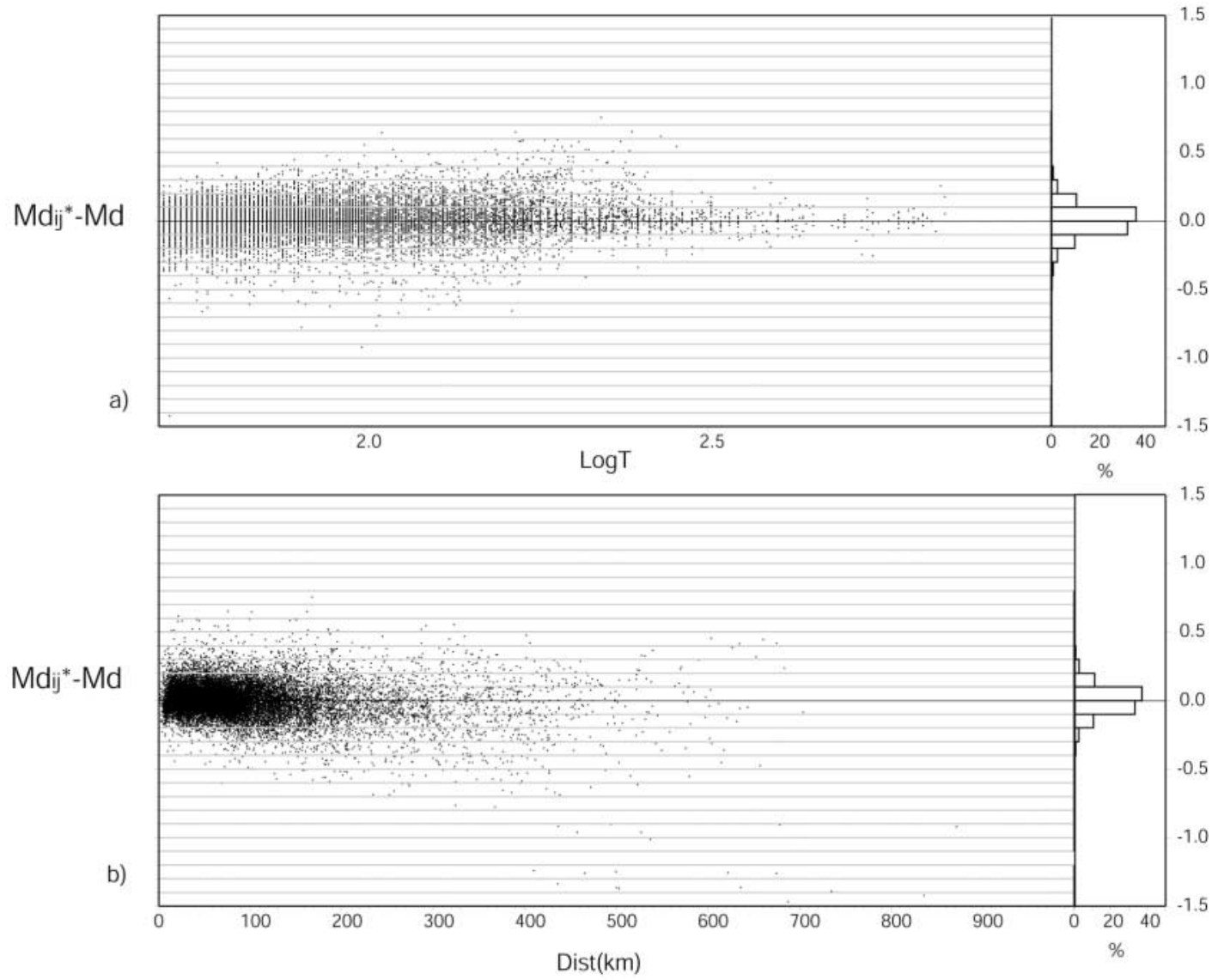

Figure 5. Residual values $M_{\mathrm{d}_{i j}}^{*}-M_{\mathrm{d}}$ versus $\log (T)$ (a) and versus epicentral distances $\triangle$ (b). Residuals are distributed between twice standard deviation $(2 \sigma=0.28)$ (histograms on the right).

\section{Revised Local and Duration Magnitude Catalog}

$M_{\mathrm{D}}$ scale parameters calibrated with station corrections are applied to the duration estimates of the Italian relocated earthquake catalog 1981-2002 to obtain an Italian seismicity catalog with revised magnitudes. The range of applicability is $1.5-2.9$ for $\log (T)$, that corresponds to $1.6-4.9 M_{\mathrm{L}}$, where $T$ is the signal duration in seconds at stations. within $100 \mathrm{~km}$ from the epicenter. We could estimate 37,653 magnitudes of the 99,780 earthquakes contained in the catalogue. For earthquakes with magnitude $M_{\mathrm{L}}$ larger then 4.9, thus out of applicability of our regression, local magnitudes come from $M_{\mathrm{L}}$ MedNet (complete after 1996) and from the ICGW catalog (ICGW, 2001). For strongest $(M>4.5)$ deep earthquakes $(z>35 \mathrm{~km})$ we use $M_{\mathrm{b}}$ from the International Seismological Centre (ISC). For some of these events there is a $M_{\mathrm{w}}$ calculation from CMT Harward or from RCMT if available (Pondrelli et al., 2002).

There are, 44,151 magnitude estimates in the revised catalog, which represents $44 \%$ of the total number of located earthquakes. This percentage is due to several factors, including that during the first years of the catalog, duration estimates were not systematically computed and earthquakes were recorded only at regional networks. These events have not had magnitude estimates and are probably very small. Finally, the magnitude threshold of $1.6 M_{\mathrm{L}}$ drastically reduces the numbers of earthquakes with magnitude estimates.

The cumulative frequency-magnitude distribution (Gutenberg-Richter relation), as shown in Figure 9a, is used to portray the most direct visualization of completeness of the catalog. The cutoff magnitude $M_{\mathrm{c}}$ corresponds to 1.6 and the $b$-value is 1.0. The 4.5-5.4 magnitude range is biased by the strongest aftershocks of the 1997 Colfiorito sequence (Central Apennines). We plotted also the cumulative distribution for only Sicilian earthquakes to test the method used for computing magnitudes for this region. The higher cutoff magnitude $\left(M_{\mathrm{c}} 2.2\right)$ is the result of the higher detection magnitude threshold for stations in that region, due to an intrinsic high-noise signal (Fig. 9b).

$$
\text { Regression } \log M_{0}-M_{\mathrm{L}}
$$

We performed linear regressions for scalar seismic moment $M_{0}$ and $M_{\mathrm{w}}$ versus $M_{\mathrm{L}}$. Seismic-moment values are derived from regional centroid moment tensor estimates (Pondrelli et al., 2002). We extracted from this catalog 110 earthquakes located in Italy between 1997 and 2002, ranging 

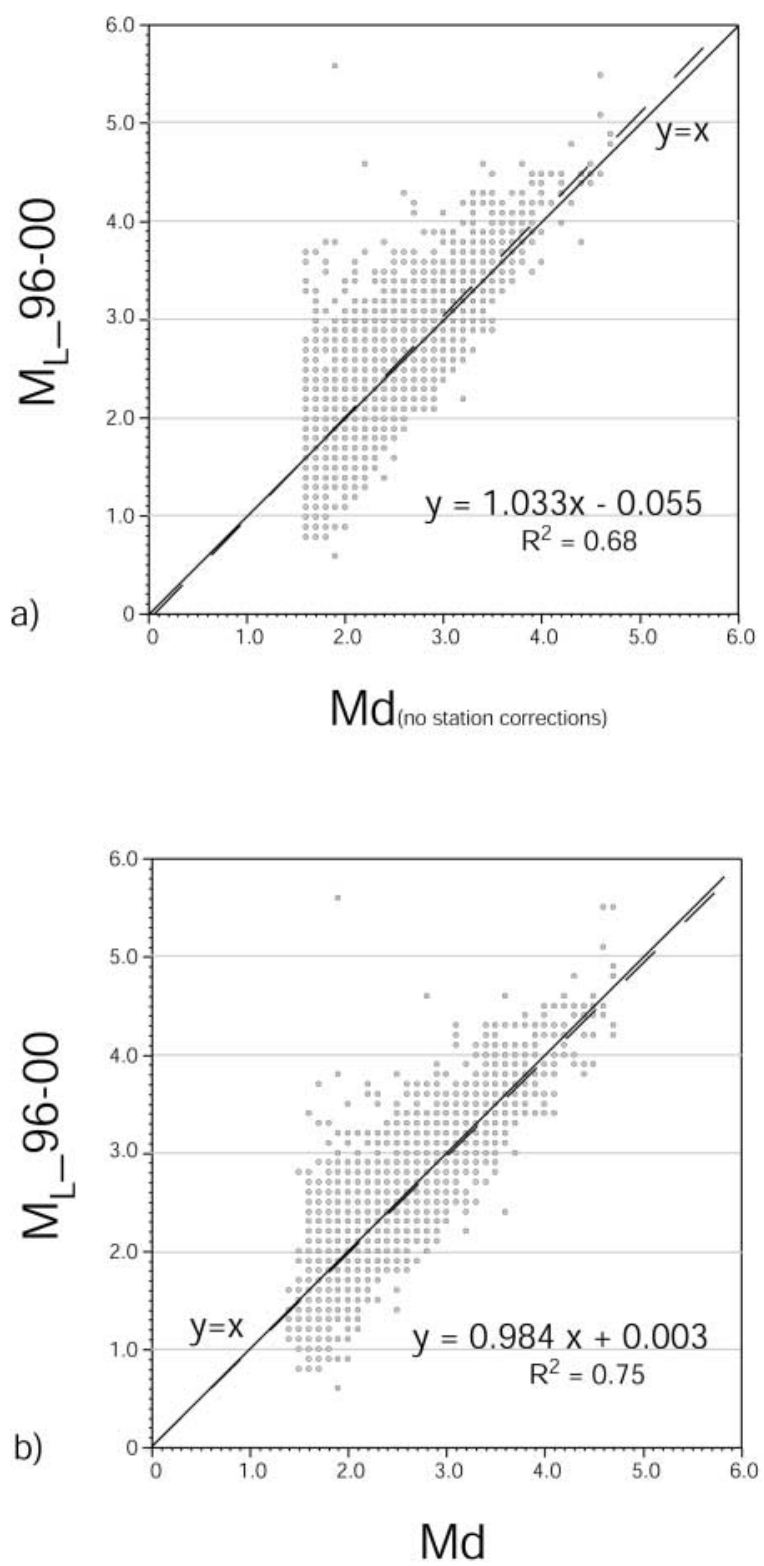

Figure 6. $4929 M_{\mathrm{d}}$ computed with this study scale (equation 3), without and with stations corrections, respectively, against $M_{\mathrm{L}}$ MedNet (1996-2000) (a, b). Black lines correspond to $y=x$, and dashed lines represent the best least-squares fit.

from $10^{15}$ to $10^{18} \mathrm{~N} \mathrm{~m}$, with $M_{\mathrm{L}}$ MedNet from 3.5 to 5.8 . Seismic moment $M_{0}$ versus $M_{\mathrm{L}}$ and $M_{\mathrm{w}}$ versus $M_{\mathrm{L}}$ plots are shown in Figure 10; the best least-squares fits are:

$$
\begin{aligned}
& \log M_{0}=1.18( \pm 0.06) \cdot M_{\mathrm{L}} \\
& +10.92( \pm 0.28), \quad R^{2}=0.76 \\
& M_{\mathrm{w}}=0.79( \pm 0.4) \cdot M_{\mathrm{L}} \\
& +1.20( \pm 0.19) \quad R^{2}=0.76
\end{aligned}
$$

Selvaggi et al. (1997) calculated the $M_{0}$ versus $M_{\mathrm{L}}$ relation-
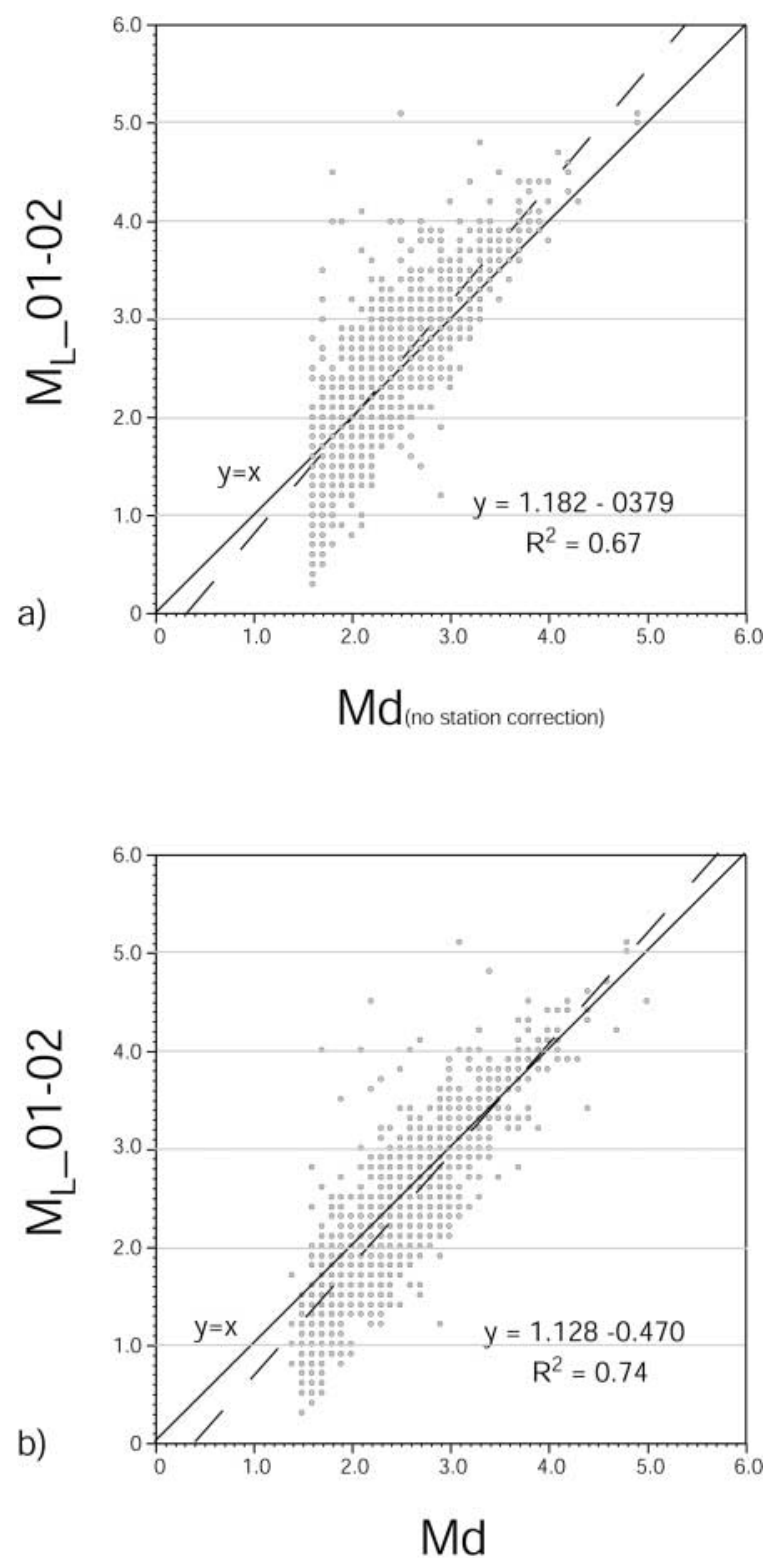

Figure 7. $1727 M_{\mathrm{d}}$ computed in this study plotted against $M_{\mathrm{L}}$ Med-Net (2001-2002), without and with stations corrections, respectively, as a test data set. Figure shows that our study $M_{\mathrm{D}}$ scale (b) strongly reduces the bias of the previous $M_{\mathrm{D}}$ scale (Console et al., 1988) (Fig. 8), corresponding well with $M_{\mathrm{L}}$ MedNet.

ship from 42 earthquakes located in Apennines (Italy) with magnitude range from $M_{\mathrm{L}} 1.5$ to 3.5. Regression coefficients are different from those of equation (7) but similar to the $\log M_{0}-M_{\mathrm{L}}$ relationship parameters obtained from northwestern Italy earthquakes of the same range of magnitude by Bindi et al. (2005). Braumiller et al. (2005) found parameters of $M_{\mathrm{L}}$ versus $M_{\mathrm{w}}$ regression similar to that of equation (8) in the same range of magnitude. The lack of linearity of $\log M_{0}-M_{\mathrm{L}}$ relationships for a large range of magnitude is well known (Bakun, 1984; Hanks and Boore, 1984; Ben- 


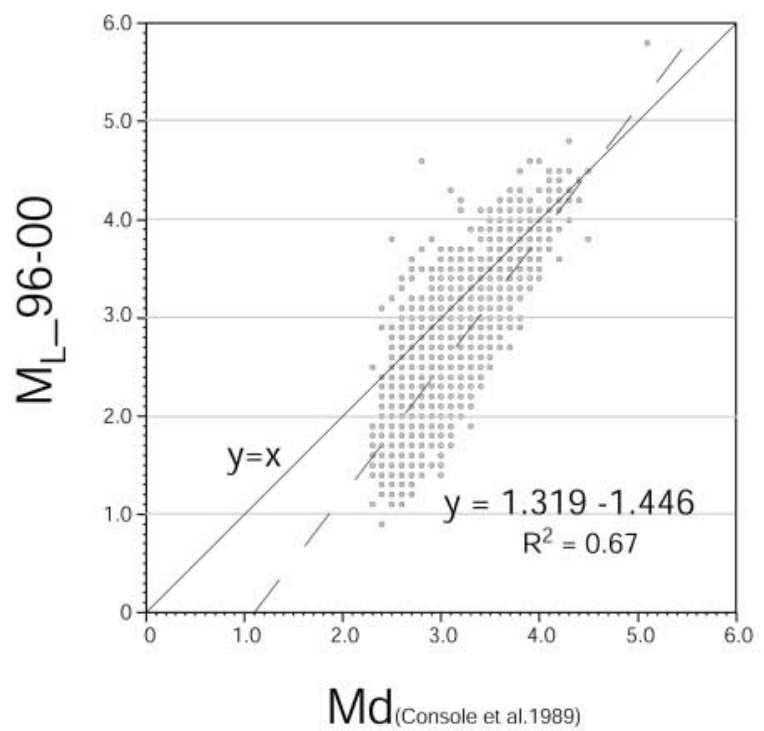

Figure 8. $\quad M_{\mathrm{d}}$ computed with previous $M_{\mathrm{D}}$ scale (Console et al., 1988) against $M_{\mathrm{L}}$ MedNet (19962000).

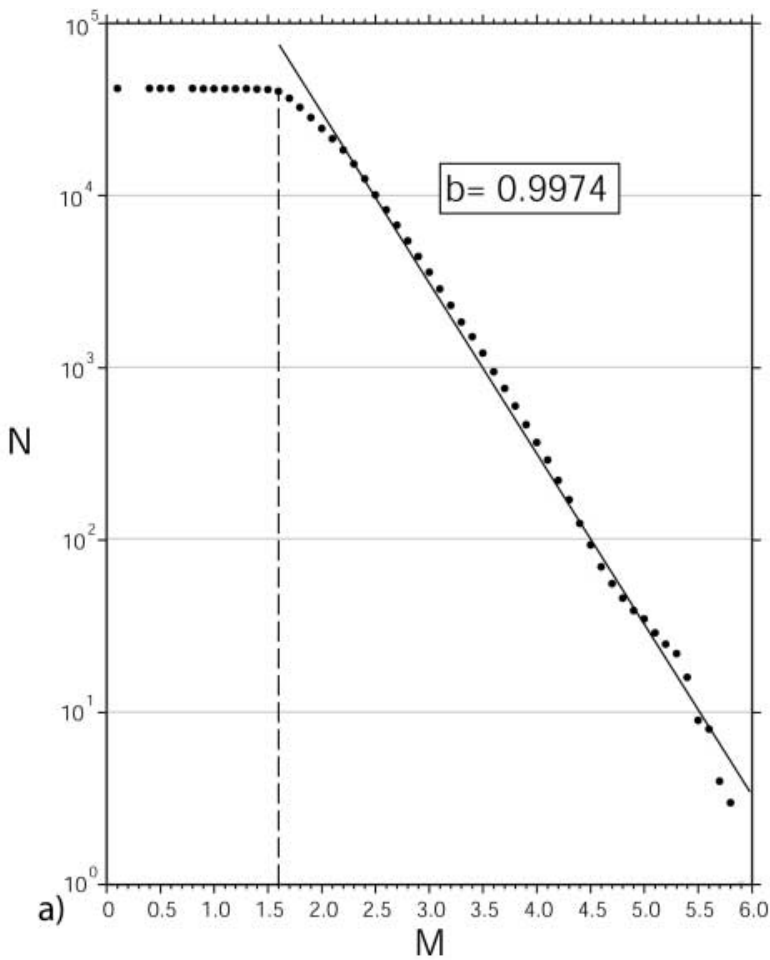

Zion and Zhu, 2002), corresponding in general to a quadratic relation. We noted that the range of our data set $\left(3.5<M_{\mathrm{L}}\right.$ $<5.8$ ) falls in a region where the data distribution is well represented by a linear relation.

\section{Conclusions and Discussion}

This work likely represents the final stage of calculating local magnitude estimates by regression analysis for the Italian earthquake catalog. Presently, local magnitude is directly determined from the growing number of broadband calibrated seismometers of the RSNC network in Italy. Nevertheless, the need to compare magnitude estimates back in time has required the work presented in this article. The $M_{\mathrm{D}}$ scale calibrated in this work reduces the previous bias between $M_{\mathrm{D}}$ and $M_{\mathrm{L}}$ estimates for Italian earthquakes recorded by the Italian seismic network (RSNC). This allows us to compile a homogeneous magnitude catalog for Italian instrumental seismicity with a completeness greater than 1.6 (the revised earthquake catalog is on the web: Italian Seismic Catalogue, CSI 1.0, Castello et al., 2005).

We have also introduced station corrections computed for RSNC seismic stations to decrease the large residuals due to the different wave propagations across Italy, such as in Sicily and Southern Calabria. Recent articles on different groundmotion scaling in Italy (Scognamiglio et al., 2005, and references therein) confirm the necessity for further investigation

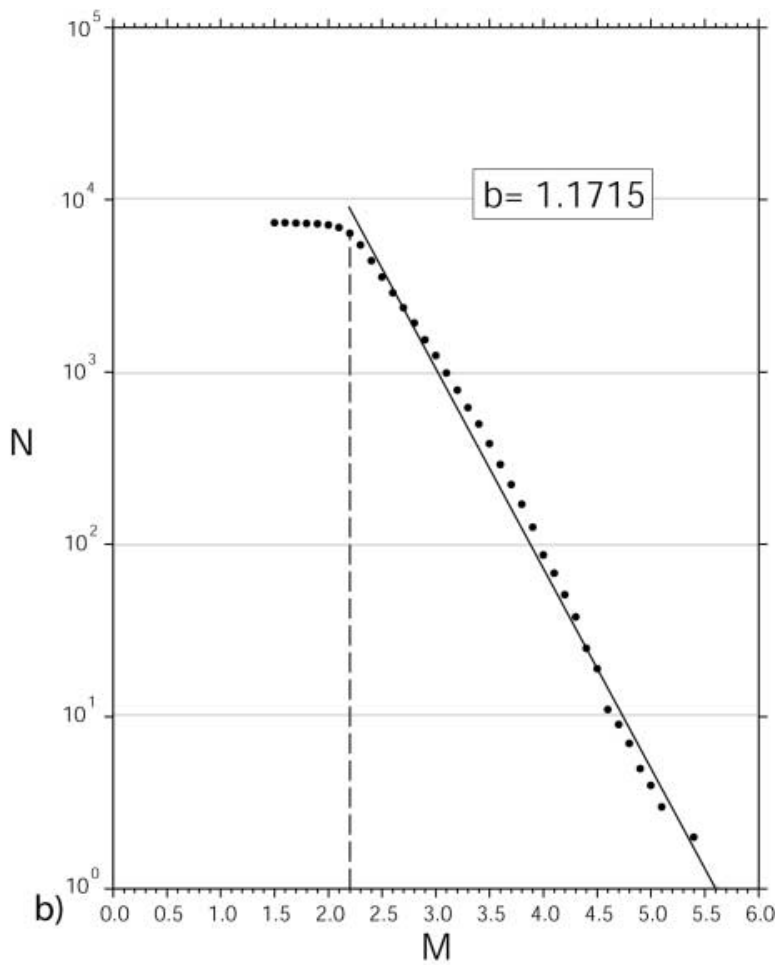

Figure 9. Cumulative distribution plot of the entire catalog (a) and cumulative distribution plot for only Sicilian earthquakes (b) as an estimation of agreement with the Gutenberg-Richter law. 

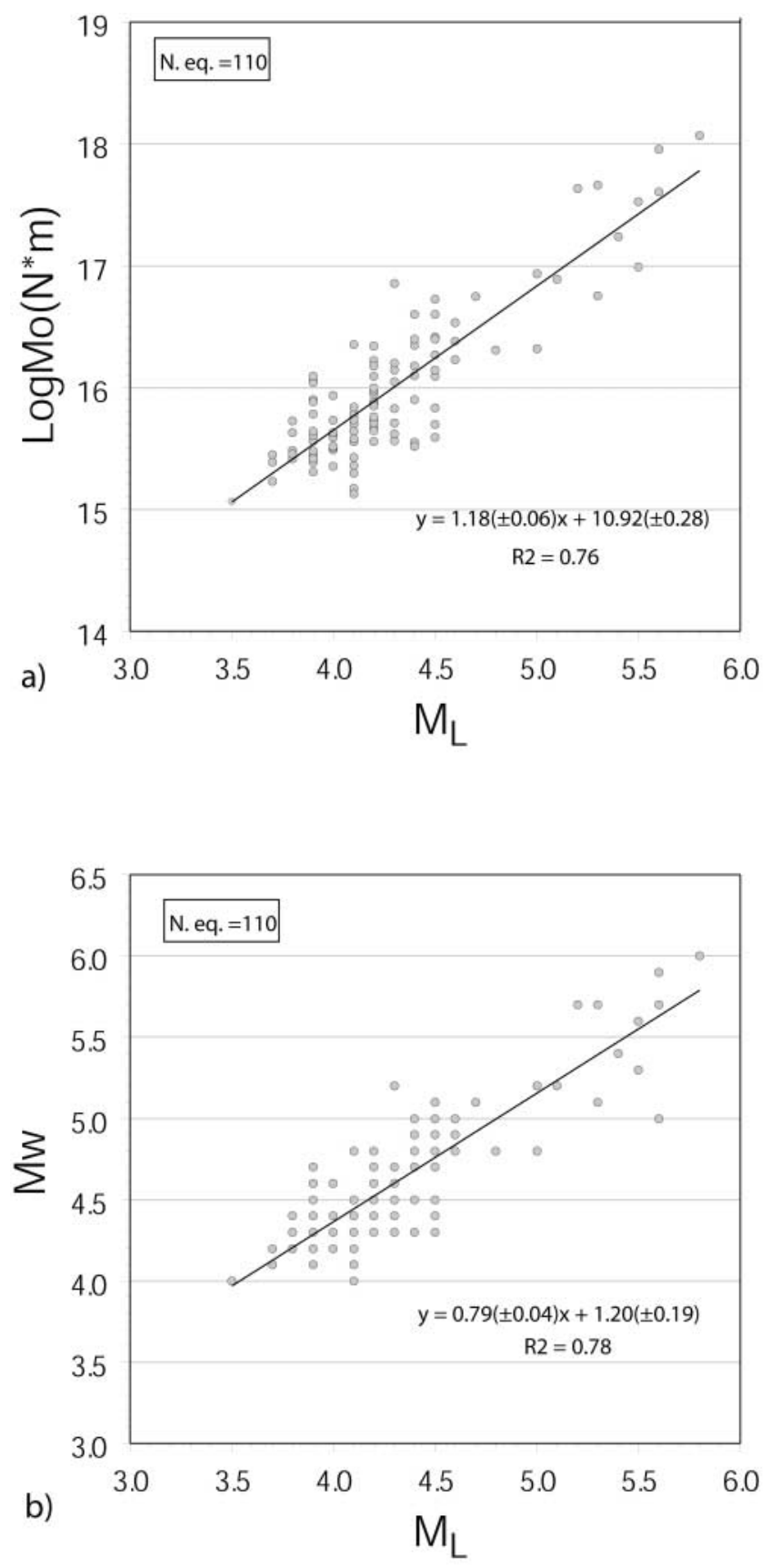

Figure 10. $\quad \log M_{0}$ and $M_{\mathrm{W}}$ versus $M_{\mathrm{L}}$. Seismic moment and $M_{\mathrm{w}}$ of 110 earthquakes located in Italy between 1997 and 2002 are from regional centroid moment tensor estimation (Pondrelli et al., 2002) $M_{\mathrm{L}}$ MedNet computed in this study.

on attenuation functions, with the aim of improving the local magnitude estimates of Italian earthquakes.

\section{Acknowledgments}

We thank M. Cattaneo for helpful suggestions and M. Di Bona, F. Mele, A. Basili, A. Marchetti, and P. Casale for fruitful discussions. We are also indebted to RSNC and regional networks staff and analysts.
The figures were drawn using GMT software (Wessel and Smith, 1991). This research has been supported in part by Project GNDT2000-2002 coordinated by A. Amato and G. Selvaggi and funded by Italian Civil Protection.

\section{References}

Bakun, W. H. (1984). Magnitudes and moments of duration, Bull. Seism. Soc. Am. 74, no. 6, 2335-2356.

Ben-Zion, Y., and L. Zhu (2002). Potency-magnitude scaling relations for southern California earthquakes with $1.0<\mathrm{M}_{\mathrm{L}}<7.0$, Geophys. J. Int., 148, F1-F5.

Bindi, D., D. Spallarossa, C. Eva, and M. Cattaneo (2005). Local and duration magnitude in Northwestern Italy and seismic moment versus magnitude relationships, Bull. Seism. Soc. Am. 95, no. 2, 592-604.

Braumiller, J., N. Deichmann, D. Giardini, S. Wiemer, and the SED Magnitude Working Group (2005). Homogeneous Moment-Magnitude calibration in Switzerland, Bull. Seism. Soc. Am. 95, no. 1, 58-74.

Carrol, R. J., and D Ruppert (1996). The use and misuse of orthogonal regression in linear errors-in-variables models, Am. Stat. 95, no. 1, $58-74$.

Castello, B., G. Selvaggi, C. Chiarabba, and A. Amato (2005). CSI Catalogo della sismicità italiana 1981-2002, v. 1.0. INGV-CNT, Rome. www.ingv.it/CSI/ (last accessed February 2005).

Chiarabba, C., L. Jovane, and R. Di Stefano (2005). A new view of Italian seismicity using 20 years of instrumental recordings, Tectonophysics 395, 251-268.

Console, R., B. De Simoni, and A. Di Sanza (1988). Riesame della relazione magnitudo-distanza, in Proceedings of the VII Conference of the Gruppo nazionale di Geofisica della Terra Solida (GNGTS), Rome, 30 November to 2 December, 51-61.

Eaton, J. P. (1992). Determination of amplitude and duration magnitudes and site residuals from short-period seismographs in Northern California, Bull. Seism. Soc. Am. 82, 533-579.

Gasperini, P. (2002). Local magnitude revaluation for recent Italian earthquakes (1981-1996), J. Seism. 6, 503-524.

Global Centroid Moment Tensor (CMT) Project catalog search, www.globalcmt.org/CMTsearch.html (last accessed July 2005).

Hanks, T. C., and D. M. Boore (1984). Moment-magnitude relations in theory and practice, J. Geophys. Res. 89, 6229-6235.

Instrumental Catalog Working Group (ICGW) (2001). Catalogo strumentale dei terremoti "italiani" dal 1981 at 1996, version 1.0, CLUEB, Bologna, CD-ROM.

International Seismological Centre (2001). Online bulletin, http:// www.isc.ac.uk/Bull, International Seismological Centre, Thatcham, United Kingdom (last accessed July 2005).

Lee, W., H. K. Bennet, and K. L. Meagher (1972). A method of estimating magnitude of local earthquakes from signal duration, U.S. Geol. Surv. Open-File Rept. 28.

Malagnini, L., R. B. Hermann, and M. Di Bona (2000). Ground-motion scaling in the Apennines (Italy), Bull. Seism. Soc. Am. 90, no. 4, 1062 1081.

Mazza, S., A. Morelli, and E. Boschi (1998). Near real-time data collection and processing at MEDNET, EOS Trans. AGU 79, F569.

Michaelson, C. A. (1990). Coda duration magnitudes in Central California: an empirical approach, Bull. Seism. Soc. Am. 80, no. 5, 1190-1204.

Mouayn, I., B. A. Tadili, 1. A. Brahim, M. Ramdani, M. Limouri, and N. Jabour (2004). Duration Magnitude Scale and Site Residuals for Northern Morocco, Pure Appl. Geophys. 161, 1061-1080.

National Earthquake Information Center (NEIC) (2005). Online PDE catalog, http://neic.usgs.gov/neis/ (last accessed July 2005).

Pondrelli, S., A. Morelli, G. Ekström, S. Mazza, E. Boschi, and A. M. Dzewonski (2002). European-Mediterranean regional centroidmoment tensors: 1997-2000, Phys. Earth Planet. Interiors 130, $71-$ 101. 
Real, C. R., and T. Teng (1973). Local Richter magnitude and total signal duration in Southern California, Bull. Seism. Soc. Am. 63, no. 5, 18091827.

Scognamiglio, L., L. Malagnini, and A. Akinci (2005). Ground-motion scaling in Eastern Sicily, Italy, Bull. Seism. Soc. Am. 95, no. 2, 568578.

Selvaggi, G., B. Castello, and R. M. Azzara (1997). Spatial distribution of scalar seismic moment release in Italy (1983-1996): seismotectonic implications for the Apennines, Ann. Geofis. 40, no. 6, 1565-1578.

Stroymer, D., G. Grünthal, and R. Wahlström (2004). Chi-square regression for seismic strength parameter relations, and their uncertainties, with applications to an $\mathrm{M}_{\mathrm{w}}$ based earthquake catalogue for central, northern and north-western Europe, J. Seism. 8, 143-153.

Wessel, P., and W. H. F. Smith (1991). Free software helps map and display data, EOS Trans. AGU 72, 441
Istituto Nazionale di Geofisica e Vulcanologia

Centro Nazionale Terremoti

Via di Vigna Murata, 605

00176 Rome, Italy

(B.C., M.O.)

Istituto Nazionale di Geofisica e Vulcanologia Centro per la Sismologia e l'Ingegneria Sismica

Via Castello d'Aquino 13

83035 Grottaminarda (AV), Italy

(G.S.)

Manuscript received 16 December 2005. 